\title{
Correction to: Description and phylogenetic relationships of a new genus of sea cucumbers from Australia, with two new combinations (Holothuroidea, Stichopodidae)
}

\author{
Sau Pinn Woo ${ }^{1} \cdot$ Hiroshi Kajihara ${ }^{1} \cdot$ Maria Byrne $^{2} \cdot$ Toshihiko Fujita $^{3}$
}

Published online: 8 November 2019

(C) Senckenberg Gesellschaft für Naturforschung 2019

\section{Correction to: Marine Biodiversity} https://doi.org/10.1007/s12526-019-00974-8

In the originally published version of the article, Fig. 1 caption contains errors. Figure 1 is shown below with the correct caption.

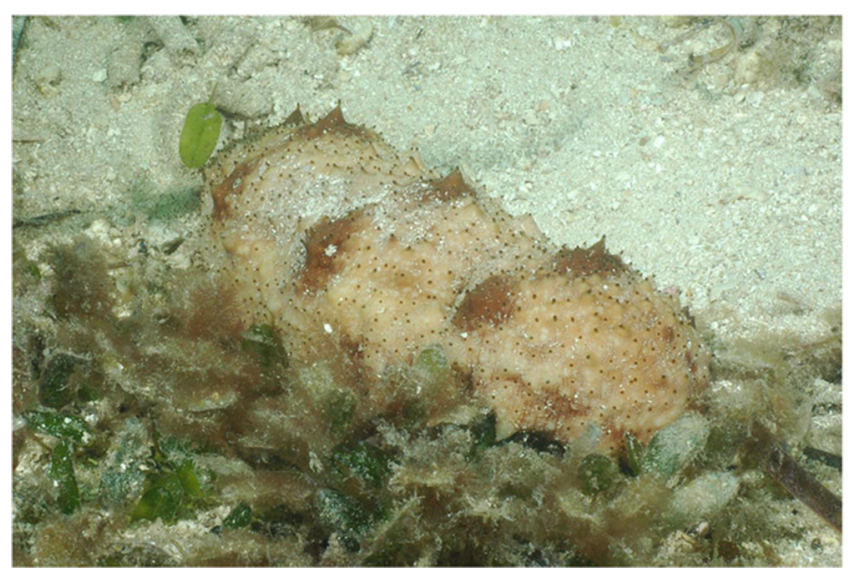

Fig. 1 In situ photograph of Notostichopus ludwigi (Erwe, 1913) from Jurien Bay, Western Australia; approximately $10 \mathrm{~cm}$ in length. Photo by Dr. Graham Edgar

The online version of the original article can be found at https://oi.org/ 10.1007/s12526-019-00974-8

Sau Pinn Woo

abe_woo@hotmail.com

1 Centre for Marine and Coastal Studies, Universiti Sains Malaysia, 11800 Penang, Malaysia

2 School of Medical and Biological Sciences, F13 Anderson Stuart, The University of Sydney, Sydney, NSW 2006, Australia

3 Department of Zoology, National Museum of Nature and Science, 4 1-1 Amakubo, Tsukuba, Ibaraki 305-0005, Japan 